\title{
Bilateral thumb polydactyly: Case report
}

\author{
Monsef ELABDI ${ }^{1}{ }^{*}$, Majdouline BENCHAFAI ${ }^{2}$, Abdeloihab JAAFAR ${ }^{1}$ \\ ${ }^{1}$ Department of Orthopaedic Surgery «1», Military Hospital of Instruction Mohammed V, Rabat, Morocco \\ ${ }^{2}$ Department of pediatric medical emergencies, university hospital Ibn Sina, Rabat, Morocco
}

\section{Email address:}

elabdimonsef@gmail.com (M. Elabdi), majdouline22@hotmail.com(M. BENCHAFAI), ajaafar02@gmail.com (A. Jaafar)

\section{To cite this article:}

Monsef ELABDI, Majdouline BENCHAFAI, Abdeloihab JAAFAR. Bilateral Thumb Polydactyly: Case Report. Advances in Surgical Sciences. Vol. 1, No. 3, 2013, pp. 17-19. doi: 10.11648/j.ass.20130103.12

\begin{abstract}
Polydactyly is the most common congenital digital anomaly of the hand. Surgical treatment is rewarding. In this article, we describe the case of a 15-year-old male who was presenting thumb bilateral polydactyly. The diagnisis was clinic, completed by radiography which has objectified the anomaly type according to Wassel's classification. Operated in our hospital, he received a repair surgery at the level of his right hand by resection of supernumerary hypoplastic thumb, with restoration and anatomical reconstruction of the dominant thumb. He was discharged with no complications. The patient and his family were satisfied with the cosmetic and functional result. We discuss types of duplications, and principle of therapeutic approach of this pathology.
\end{abstract}

Keywords: Polydactyly, Thumb, Duplication, Supernumerary Digit

\section{Introduction}

Duplication of the thumb is the most common congenital anomaly of the hand [1-3]. It can be isolated or associated with other abnormalities in several syndromes [4]. Different types of thumb polydactyly, classified by Wassel into 7 types according to the level of bifurcation, and the extent of the deformation [5].

There are variable therapeutic methods; therefore, the treatment choice depends on the polydactyly group, and the duplication variation [6-8]. It also requires an evaluation of the bone and surrounding structures.

We report a 15 year-old male case with bilateral thumb duplication, but of different types. We operated the right side. The evolution was satisfactory. We consider that this result is important to report.

\section{Case Report}

A 15 year old male was admitted because of bilateral hand polydactyly, that he had since his birth. Physical examination revealed thumb bilateral preaxial duplication (1).

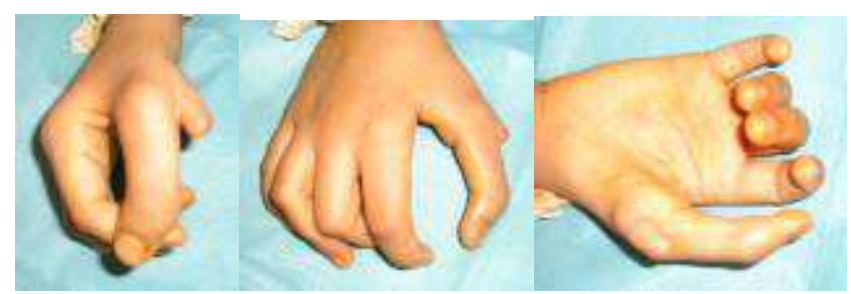

(a)

(b)

(c)

Figure 1. Right hand type IV thumb polydactyly.

Cubital thumbs had a dominant appearance, with ulnar deviation of the distal phalanxes. Function of the hands was influenced and disrupted, with difficulties working. The extra radial fingers were hypoplasic, devoid of the nails, divergent, and without active movement. There was no other associated congenital anomaly. Standard radiograph demonstrated picture of metacarpal duplication of the left thumb evocating Wassel type VI. In the right hand, X-rays showed a duplicated proximal phalanx of the right thumb simulating a type IV (2). 


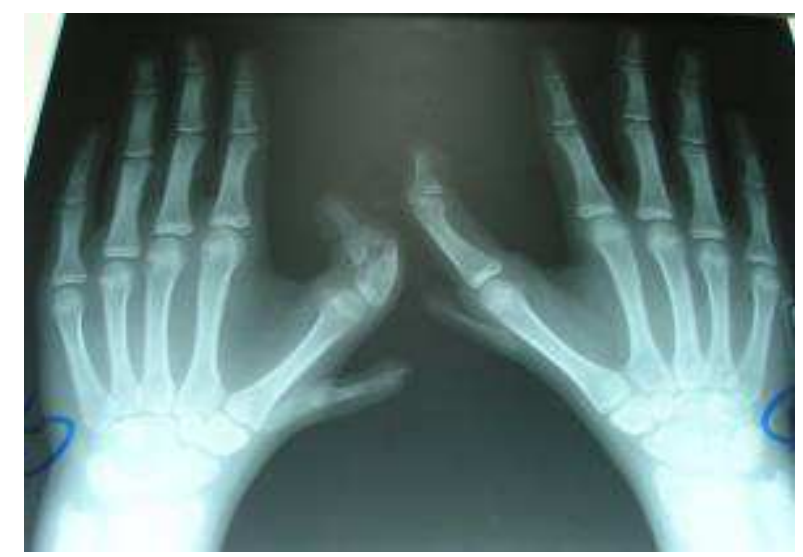

Figure 2. Bilateral thumb polydactyly, with right hand type IV, and left hand type VI, X-ray appearance.

The patient was treated at the right side. He underwent a resection of the most hypoplastic digit with perfect regularization. Although dominant thumb situated to the top of the first metacarpal (M1), the surgical procedure was based on anatomical restoration of deformities by osteotomie of M1 which was closed by a nonabsorbable fixing wire, and alignment of the phalanges which was maintained with a pin for six weeks (3).

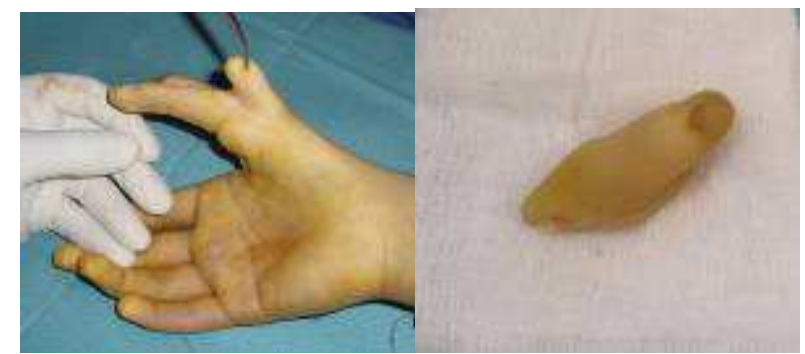

(a) Surgical incision (b) the removed supernumerary digit.

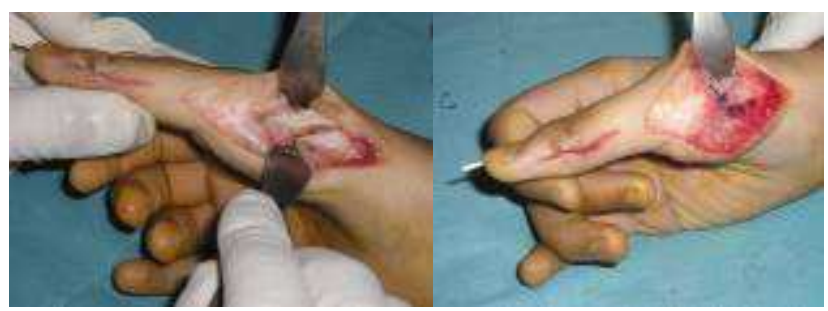

(c) osteotomie of the first metacarpal (d)fixation of the osteotomie by nonabsorbable wire

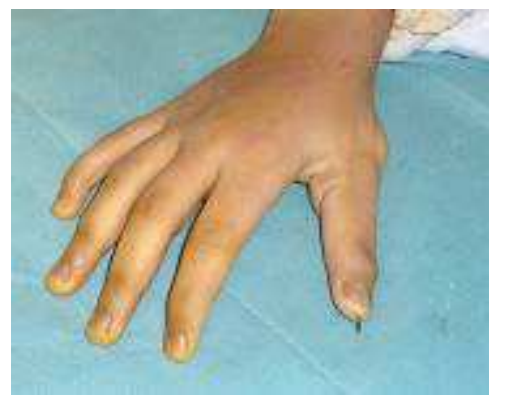

(e) alignment of interphalangeal joint

Figure 3. Reconstructive surgery of the right hand
The tendon transfer was not necessary. The patient and his parents were satisfied with the result. He benefited a good surgical correction with joint stability (4).

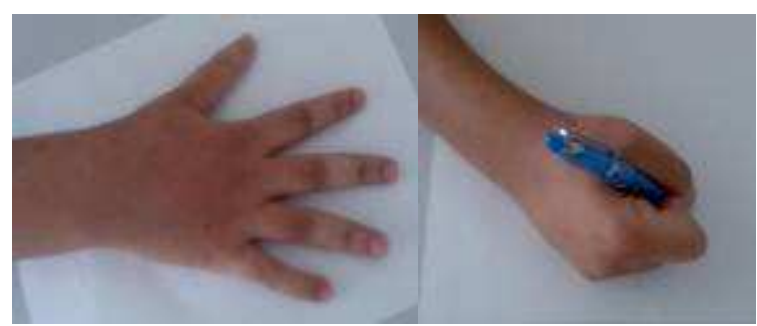

(a)

(b)

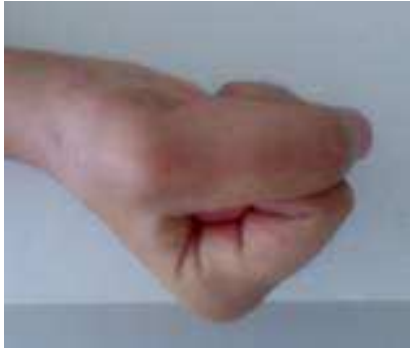

(c)

Figure 4. postoperative result showing the precise grip.

\section{Discussion}

Duplication of the thumb is the most common anomaly of the hand [1-2]. This congenital deformation pattern may be isolated or associated with other anomalies [1, 4]. Polydactyly is usually classified into three major groups: medial ray (preaxial), central ray and lateral ray (postaxial) [9], thereby it's presented according to the Wassel's classification into seven types (Type I: bifid distal phalanx. Type II: duplicated distal phalanx. Type III: bifid proximal phalanx. Type IV: duplicated proximal phalanx. Type V: bifid metacarpal. Type VI: duplicated metacarpal. Type VII: triphalangism) [5]. Although this classification based on level of duplications, it has interest in the therapeutic choice [10]. Our patient presents a type IV variation of right thumb, while on the left, the variation was type VI. The aim of surgery is to obtain a functional and cosmetical thumb [8, 11-13]. This is almost often carried during the first year, from the sixth month $[6,8$, $12,14-15]$. Resection alone is not sufficient, complementary reconstructive options concerning bone, tendons, skin and nail are necessary to restore a better thumb, and to avoid further procedures [7-8, 11, 16-18].

In our case, the lack of the treatment on the ideal time was due to refusal by the parents. Our patient is an older child aged 15. He underwent surgical correction on the right side, by resection of the additional hypoplastic thumb, with reconstruction of the dominant thumb by using an osteotomy of the first metacarpal and alignment of Interphalangeal joint (IPJ) which was angulated radially. Cosmetic result was satisfactory with remote good functional recovery.

Surgery of the left hand was decided for later to achieve a 
well planned correction in order to assess the likely objectives of the surgical intervention which's complicated in this case with the zigzag deformity.

\section{Conclusion}

Polydactyly is a most frequent congenital anomaly of the hand. However, the surgical treatment should be practiced at an early age (6-12 months), order to estimate a good evolution with the growth and to reduce complications. Nevertheless, procedures of correction in the adult may provide a better result after a thorough clinical and radiological study.

\section{Conflict of Interest}

None

\section{References}

[1] Woolf CM, Myrianthopoulos NC. Polydactyly in Ameri-can negroes and whites. J Hum Genet 1973; 25: 397- 404.

[2] Baek GH, Gong HS, Chung MS, Oh JH, Lee YH, Lee SK (2007) Modified Bilhaut-Cloquet procedure for Wassel type-II and III polydactyly of the thumb. J Bone Joint Surg Am 89:534-541

[3] Castilla E, Paz J, Mutchinick O, Muñoz E, Giorgiutti E, Gelman Z (1973) Polydactyly: a genetic study in South America. Am J Hum Genet 25:405-412

[4] Blauth W. and Olason A.T.: Classification of polydactyly of the hands and feet. Arch. Orthop. Trauma. Surg., 107: 334-344, 1988

[5] Wassel HD: The results of surgery for polydactyly of the thumb.Clin Orthop Relat Res 1969, 64:175-93.

[6] Guero S, Haddad R, Glicenstein J (1995) Surgical treatment of duplication of the thumb. Apropos of 106 cases. Ann Chir Main Memb Super 14:272-283

[7] Marie Maillet, Damien Fron, Veronique Martinot-Duquennoy , Bernard Herbaux. Results after surgical treatment of thumb duplication: a retrospective review of 33 thumbs. J Child Orthop (2007) 1:135-141

[8] Nicola Mumoli1*, Daniele Gandini2, Edris Kalanzi. Left hand polydactyly: a case report. Cases Journal 2008, 1:346 doi:10.1186/1757-1626-1-346

[9] Elliott AM, Evans JA: Genotype-phenotype correlations in mapped split hand foot malformation (SHFM) patients.Am J Med Genet A 2006, 140(13):1419.27.

[10] Netscher DT: Congenital hand problems. Terminology, etiology, and management.Clin Plast Surg 1998, 25(4):537-52.

[11] Mustafa Nişanc1, Muhitdin Eski, Yakup Çil, Mustafa Şengezer. An atypical thumb duplication: case report. Gulhane Med J. 2005; 47(3): 224-227

[12] Nguyen Ngoc Hung. Bifid thumb type IV in children: transferring an epiphyseal segment of the proximal phalanx with insertion of the abductor pollicis brevis tendon. J Child Orthop (2010) 4:525-537

[13] James MA (2001) Congenital hand malformations. In: Chapman MW (ed) Chapman's orthopaedic surgery, 3rd edn. Lippincott Williams \& Wilkins, Philadelphia, pp 4197-4240

[14] Cohen MS (1998) Thumb duplication. Hand Clin 14:17-27

[15] Samson P, Salazard B, Magalon G (2004) The "Bilhaut-Cloquet" technique for treatment of thumb duplication. Handchir Mikrochir Plast Chir 36:141-145

[16] Netscher DT, Baumholtz MA: Treatment of congenital upper extremity problems.Plast Reconstr Surg 2007, 119(5):101e-129e. PubMed Abstract | Publisher Full Text

[17] Hung L, Cheng JC, Bundoc R, Leung P. Thumb duplication at the metacarpophalangeal joint: Management and a new classification. Clin Orthop 1996; 323: 31-41

[18] Light TR (1991) Duplication du pouce. Pathologie et traitement. In: Gilbert A, Buck-Gramcko D, Lister G (eds) Les malformations conge'nitales du membre supe'rieur. Monographie du groupe d'etude de la main. Expansion Scientifique Franc, aise, Paris, pp 130-138 